\title{
Estudo exploratório da eficiência dos Tribunais de Justiça estaduais brasileiros usando a Análise Envoltória de Dados (DEA)
}

\author{
José Marcelo Maia Nogueira
}

Secretaria Especial de Planejamento e Gestão do Tribunal de Justiça do Estado do Ceará

Kátia Michelle Matos de Oliveira

Secretaria Especial de Planejamento e Gestão do Tribunal de Justiça do Estado do Ceará

Alan Pereira de Vasconcelos

Faculdades Nordeste

Leonel Gois Lima Oliveira

Escola Superior de Magistratura do Estado do Ceará

\begin{abstract}
O objetivo deste trabalho é comparar a eficiência relativa dos Tribunais de Justiça estadual do Brasil. Trata-se de um estudo de caráter exploratório com um enfoque quantitativo e qualitativo, com pesquisa documental e bibliográfica. Foram utilizados os dados do relatório Justiça em números, edições 2007 e 2008, publicadas pelo Conselho Nacional de Justiça. Os dados foram analisados sob enfoque de um modelo orientado para outputs usando a técnica de Análise Envoltória de Dados (DEA) para análise da eficiência dos Tribunais. Verificou-se um aumento no número de tribunais que alcançaram o nível máximo da eficiência relativa entre 2007 e 2008. Alguns tribunais foram indicados como referências para os demais. É apresentada, também, a situação do Tribunal de Justiça do Estado do Ceará junto a uma análise dos fatores que precisariam ser ajustados para o alcance de sua eficiência máxima.
\end{abstract}

Palavras-chave: Análise Envoltória de Dados; eficiência; Justiça em números.

Estudio exploratorio de la eficiencia de los Tribunales de Justicia de los estados brasileños mediante el Análisis Envolvente de Datos (DEA)

El objetivo de este trabajo es comparar la eficiencia relativa de los Tribunales de Justicia de los Estados de Brasil. Este es un estudio exploratorio con un enfoque cuantitativo y cualitativo, con investigaciones documentales y bibliográficas. Utilizaronse datos del informe Justiça em números, para 2007 y 2008 , publicados por el Consejo Nacional de Justicia. Los datos fueron analizados utilizando el modelo orientado a resultados con la técnica del Análisis Envolvente de Datos (DEA) para evaluar la eficiencia de

Artigo recebido em 14 nov. 2011 e aceito em 13 jul. 2012.

Rev. Adm. Pública - Rio de Janeiro 46(5):1317-340, set./out. 2012 
los Tribunales. Percibimos un aumento en el número de tribunales que han alcanzado el máximo nivel de eficiencia relativa entre 2007 y 2008. Algunos tribunales han sido presentados como referencias a otros. Además, se ha presentado un análisis de lo Tribunal de Justicia del Estado de Ceará, con énfasis en los factores que necesitan ser ajustados para alcanzar su eficiencia máxima.

Palabras clave: Análisis Envolvente de Datos; eficiencia; Justiça em números.

Exploratory study of the efficiency of Brazilian State Justice Courts using the Data Envelopment Analysis (DEA)

The main objective of this paper is to compare the relative efficiency of the States Justice Courts of Brazil. This is an exploratory study with a focus on quantitative and qualitative research with documentary and bibliography researches. They used data in the report Justiça em números, editions 2007 and 2008, published by the National Council of Justice. The data were analyzed using the model oriented for outputs using the technique of Data Envelopment Analysis (DEA) to assess the efficiency of the Courts. There was an increase in the number of courts that have reached the maximum level of relative efficiency between 2007 and 2008. Some Justice Courts have been presented as benchmarks for all other Courts. In addition, it has presented the situation of the Justice Court of the State of Ceará together with an analysis of the factors that need to be adjusted to achieve its maximum level of efficiency.

KEY words: Data Envelopment Analysis; efficiency; Justiça em números.

\section{Introdução}

Desde as reformas em curso na organização e no funcionamento do Estado, observadas nas últimas décadas, é percebida uma tendência mundial na administração pública que tem se pautado pela adoção de instrumentos de gestão visando à medição do desempenho em agências e órgãos públicos, bem como do incremento de sua eficiência e resultados. Na tentativa de adequação a esse cenário, tornou-se comum, por parte dessas organizações, a elaboração e o uso de sistemas de mensuração que se propõem a conhecer melhor seus desempenhos organizacionais. Entre outros objetivos, a utilização estratégica de sistemas capazes de mensurar o desempenho e a eficiência de um órgão público possibilita práticas mais otimizadas de controle, orçamento, aprendizagem organizacional e consequente melhoria dos serviços prestados (Behn, 2003).

Em todo o mundo, as primeiras reformas que enfatizam essas diretrizes se deram no Poder Executivo, durante a década de 1980. Mais recentemente, movimentos de reforma visando melhores resultados, transparência e eficiência passaram a se instalar nos Poderes Legislativo e Judiciário (isto é, em países onde vigora a tripartição do poder de Estado). No Brasil, um dos principais marcos para o fomento da discussão e fortalecimento desses movimentos se deu com a inclusão do princípio da eficiência como um dos princípios constitucionais da administração pública. ${ }^{1}$ Coincidindo com essas e outras transformações (administrativas e

\footnotetext{
${ }^{1}$ Segundo a Constituição Federal de 1988, “a administração pública direta e indireta de qualquer dos Poderes da União, dos Estados, do Distrito Federal e dos Municípios obedecerá aos princípios de legalidade, impessoalidade,
} 
de demandas de serviço, por exemplo), o Poder Judiciário passa também a buscar respostas às pressões sobre ele exercidas por melhorias na prestação de seus serviços e de sua gestão (Nogueira, 2010).

Tentando identificar problemáticas a serem trabalhadas neste poder, o estudo $\mathrm{A}$ imagem do Judiciário junto à população brasileira, do Centro de Pesquisas de Opinião Pública da UnB (Universidade de Brasília, apud Vieira e Pinheiro, 2008), conclui que, atualmente, a justiça no Brasil não atende bem às necessidades do povo brasileiro, tem problemas de gestão e de planejamento, precisa de reformulações, é lenta e não oferece tratamento igualitário a seus demandantes. Por sua vez, em pesquisa que aborda possíveis causas para as altas taxas de congestionamento processual no Judiciário brasileiro, Sadek (2009:1) considera que "o desempenho do Judiciário depende estritamente da gestão administrativa interna. De nada adianta ter mais juízes, mais computadores, mais unidades judiciais, sem uma gestão adequada". Diante desse cenário, a crise do Judiciário (tal qual caracterizada pelo estudo da UnB) tem recebido, nos últimos anos, críticas e proposições visando sua amenização, que perpassam variadas abordagens, normalmente pautadas por tentativas de reformulação legal e administrativa.

A exemplo das medidas gerenciais que buscavam lidar com a crise do Estado, o Poder Judiciário brasileiro começa a considerar mais fortemente o tema da reforma de sua gestão a partir da primeira metade da década de 1990. Anos depois, em 2004, é promulgada a Emenda Constitucional no 45/2004, conhecida por "Reforma do Judiciário", que traz, como uma de suas principais realizações, a criação do Conselho Nacional de Justiça (CNJ) — órgão responsável pelo controle administrativo e financeiro do Poder Judiciário brasileiro.

O CNJ, pautando-se pela citada tendência de desenvolvimento de sistemas de mensuração de desempenho, a partir de 2006 passa a recolher e sistematizar dados estatísticos referentes a aspectos diversos identificados como diretamente ligados ao desempenho das organizações judiciárias brasileiras (tais quais seus insumos, dotações orçamentárias e aspectos sobre litigiosidade e acesso à justiça). A divulgação desses dados vem então a ser feita por intermédio de relatório anual intitulado Justiça em números.

Paralelamente, no campo da medição de eficiências produtivas e organizacionais, surge uma técnica de construção de fronteiras de produção com a utilização de indicadores de eficiência produtiva conhecida como Date Envelopment Analysis (DEA) ou Análise Envoltória de Dados. Ela permite uma análise técnica de unidades produtivas que utilizam múltiplos insumos para a produção de múltiplos bens ou serviços (Peña, 2008).

Segundo Peña (2008:84), a DEA, entre outras finalidades, também é recomendada para os estudos da eficiência da administração pública que operacionalizam suas atividades em unidades organizacionais. Portanto, tal ferramenta permite que as organizações judiciárias brasileiras possam ser avaliadas conforme sua eficiência produtiva, considerando a prestação

moralidade, publicidade e eficiência" (BRASIL, 1988/2009). O princípio da eficiência é inserido no art. 37 da Constituição Federal do Brasil pela Emenda Constitucional no 19/1998. 
jurisdicional como um processo produtivo. O princípio da eficiência ganha maior enfoque permitindo aprimoramentos e melhorias na gestão do Poder Judiciário.

Dessa forma, o presente trabalho visa a apresentar uma análise da eficiência organizacional do segmento estadual do Judiciário brasileiro via DEA, através do uso dos dados já levantados para informação do Justiça em números por todos os Tribunais de Justiça estaduais do país. Tem como objetivos específicos: apresentar a medição do nível de eficiência dos Tribunais de Justiça estaduais brasileiros nos anos de 2007 e 2008 no primeiro grau de instância judicial; fazer uma projeção de um Tribunal de Justiça para o alcance do nível máximo de eficiência relativa; identificar tribunais que, na lógica da eficiência relativa, servem de referência para outros tribunais.

Vale ressaltar que a presente pesquisa busca, também, diminuir a lacuna existente quanto ao estudo da temática de gestão do Poder Judiciário, uma vez que se verifica um desequilíbrio entre os três poderes enquanto objetos de estudo no campo científico da Administração Pública. Aragão (1997) e Arantes (2007) alertam sobre a exiguidade de estudos e pesquisas sobre o Poder Judiciário na área de administração pública no Brasil. Por sua vez, a pesquisa desenvolvida por Nogueira (2011) demonstra que menos de 1\% dos trabalhos acadêmicos retrata o tema "gestão do Poder Judiciário" quando observados os anais dos principais encontros de pós-graduação e pesquisa em administração do país e os periódicos relacionados à administração pública brasileira no período de 1995 a 2008.

Assim, no presente trabalho, primeiramente, será desenvolvido um referencial teórico sobre a gestão e a eficiência do Poder Judiciário brasileiro, contextualizando o cenário e apresentando o relatório Justiça em números. Em seguida, será enfocada a Análise Envoltória de Dados e sua forma de utilização para a medição da eficiência da unidade produtiva. Na quarta seção será apresentada a metodologia adotada, bem como as análises e resultados dos dados obtidos. Por fim, são expostas as considerações finais e as referências utilizadas.

\section{Gestão e eficiência do atual Poder Judiciário brasileiro}

A ampliação da garantia de direitos fundamentais e a extensão do acesso a novos atores políticos quanto à possibilidade de contestação da constitucionalidade de leis, ambas conferidas pela Constituição Federal (CF) de 1988, intensificaram a procura pelos serviços do Poder Judiciário no Brasil, acarretando a necessidade por significativas mudanças na natureza administrativa desse poder. Nos diversos segmentos judiciais, os processos ingressados por ano tiveram suas quantidades acrescidas na ordem de centenas de milhares a milhões, normalmente com significativo crescimento anual a partir da promulgação da CF $1988 .^{2}$ Martins Filho (2009), baseado em dados do relatório Justiça em números de 2008, traz um resumo das quantidades aproximadas de processos judiciais em tramitação na Justiça brasileira, onde

\footnotetext{
2 Para análise aprofundada, ver Sadek (1999).
} 
também são informadas as quantidades aproximadas de juízes e servidores por segmento judicial:

Tabela 1

Quantidades de juízes, servidores e processos por segmento judicial

(dados de 2008)

\begin{tabular}{|lccc|}
\hline \multirow{2}{*}{ Segmento } & \multicolumn{3}{c|}{ Quantidades } \\
\cline { 2 - 4 } & Juízes & Servidores & Processos \\
\hline Justiça Federal & 1.478 & 34 mil & 6 milhões \\
Justiça do Trabalho & 3.145 & $43 \mathrm{mil}$ & 7 milhões \\
Justiça Estadual & 11.108 & $216 \mathrm{mil}$ & 48,5 milhões \\
TOTAL & 15.731 & $293 \mathrm{mil}$ & 61,5 milhões \\
\hline
\end{tabular}

Fonte: Adaptado de Martins Filho (2009).

Esse expressivo aumento da procura pelos serviços judiciários, ao ter de ser tratado pelas estruturas organizacionais então vigentes, passa a colaborar com a crise institucional e de gestão na qual ingressa o Poder Judiciário nos anos seguintes à promulgação da CF 1988. Outras manifestações dessa crise incluem fatores de natureza processual, estrutural e de gestão: número excessivo de recursos processuais, excesso de formalismo procedimental, abundância de leis, difícil acesso ao Judiciário por vários setores da população, número insuficiente de magistrados e servidores, pouca informatização das unidades judiciais, falta de planejamento estratégico, deficiência no controle administrativo, dificuldade de integração com outras instituições judiciais e operacionais, como Ministério Público, Defensoria Pública e Polícia, entre outros (Vieira e Pinheiro, 2008).

\subsection{Crises administrativas do Estado e do Judiciário e suas reformas}

De maneira mais ampla, é possível constatar que a assim caracterizada crise do Judiciário apresenta fatores comuns à crise do Estado que pôde ser percebida nas décadas de 1980 e 1990 no Brasil. De fato, a separação dessas duas crises só se faz válida por propósitos didáticos, pois ambas comportam-se como indivisíveis, imbricadas e mutuamente influentes, sendo a crise do Judiciário inserida na crise mais ampla que afetou o Estado brasileiro no período considerado.

Porém, mesmo sendo essas duas crises analiticamente indivisíveis, as tentativas de reforma têm apresentado consequências distintas sobre uma e outra. Há análises que apontam para um agravamento da crise do Judiciário causado justamente por medidas adotadas na tentativa de combate à crise do Estado (por exemplo, medidas guiadas por diretrizes de Estado mínimo e ações voltadas à racionalização de recursos públicos). Barbosa (2007:2) elenca 
fatores cruciais ao citado agravamento, além de interligá-los a condições de funcionamento do Judiciário e sua imagem perante a sociedade brasileira:

No Brasil, o protagonismo do Judiciário pós Constituição de 88 foi uma consequência, entre outros fatores, da constitucionalização de direito, do fortalecimento de novos atores sociais e da omissão do poder público em assegurar a dignidade humana e realizar o efetivo estado democrático de direito, fatores que ocasionaram uma explosão da demanda. Embora preste uma atividade jurisdicional insuficiente e ineficaz, o Judiciário é ainda percebido socialmente como o último recurso de que dispõe o cidadão para ver assegurados direitos fundamentais mínimos.

Na mesma linha, Arantes (2007:100) acrescenta:

O Judiciário, que se havia expandido na fase anterior justamente para participar da implementação da legislação social, em vez de retroagir na mesma proporção que o Estado social em crise, viu-se ainda mais exigido nesse contexto dúbio de escassez de recursos públicos e de direitos legislados abundantemente. Se na fase anterior já era difícil garantir a efetividade desses direitos pela via judicial, agora a situação de crise do Estado torna o quadro mais dramático, combinando elevação das demandas e baixa capacidade de resposta do Judiciário.

Em ambas as crises, tanto do Estado, quanto do Judiciário, o tema da gestão pública voltada para resultados torna-se central, a partir das décadas de 1980 e 1990. O debate sobre as reformas estruturais consideradas necessárias passa a dar ênfase a experimentos que visassem à otimização de procedimentos de um órgão ou poder público, visando melhorias no serviço que estes se designam a prestar ao cidadão. ${ }^{3}$

Em tentativa de reação à crise do Estado brasileiro, é criado, em 1995, o Ministério da Administração Federal e da Reforma do Estado (Mare), fruto do mesmo movimento que seria, em parte, legalmente identificado pelo objeto da Emenda Constitucional no 19/1998 que, entre outras realizações, incluiu o princípio da eficiência no art. 37 da CF 1988. O âmbito de atuação do Ministério, conforme explicitado pelo então ministro Bresser-Pereira, circunscrevia-se à reforma do aparelho administrativo do Estado especificamente, não tendo competências para tratar da reforma lato sensu do Estado; limitava-se à esfera do Poder Executivo federal, não cabendo ao ministério apresentar propostas para outras reformas estruturais consideradas necessárias à época, entre elas a reforma política e a reforma do Judiciário (Bresser-Pereira, 1996). Ainda assim, o intenso debate sobre as propostas contidas no Plano Diretor da Reforma do Aparelho do Estado (Brasil, 1995), documento elaborado pelo Mare que apresentou as diretrizes da política para a gestão pública, teve desdobramentos junto às

\footnotetext{
${ }^{3}$ É ampla a literatura sobre a chamada "nova gestão pública", englobando o conjunto de ações empreendidas nas últimas três décadas visando aumentar a eficiência e a efetividade das ações do Estado, em todo o mundo. Uma síntese das propostas e de suas inspirações teóricas é realizada por Kettl (1997).
} 
demais esferas de poder e, em menor escala, junto ao Poder Legislativo nas diversas instâncias da federação brasileira. Já o Poder Judiciário mostrou-se refratário às novas propostas. Bresser-Pereira (1999:9), acerca de sua experiência como ministro do Mare, afirma:

Apenas um setor importante da alta administração pública brasileira não revelou apoio à reforma, embora também não tenha demonstrado resistência: o Poder Judiciário. Fiz várias tentativas de falar e debater com juízes e promotores, mas sem sucesso. Logrei conversar com juristas do Direito Administrativo, mas suas reações foram antes negativas que positivas.

A percepção de Bresser-Pereira é compatível com a constatação de que o movimento institucional visando uma significativa amenização da crise no Judiciário mostrou-se bem mais modesto se comparado à velocidade de criação e ao alcance obtido pelo Mare na segunda metade dos anos 1990. No entanto, a "falta de apoio" citada pelo autor tem raízes não somente no fato de a questão gerencial trazida pela reforma ser, à época, uma novidade para todo o serviço público brasileiro, mas também na existência de certas particularidades da gestão do Poder Judiciário que, neste aspecto, o diferenciam dos demais poderes.

Referindo-se a características da gestão do Judiciário, O’Toole e Meier (apud Meier, 2007) tratam da interação existente no Judiciário com relação à sua gestão, suas características institucionais e aos fatores externos que influenciam sua administração. Segundo os autores, a gestão interna das organizações judiciárias normalmente não é objeto de atenção dos magistrados, pois a legitimidade do Poder Judiciário repousa não em sua gestão interna (entendida como os aspectos relativos à hierarquia interna e às operações regulares), ${ }^{4}$ mas em fatores relacionados à gestão externa e às ações voltadas à criação de estruturas e institucionalização (isto é, o manejo e enfrentamento das condições do ambiente externo à organização). Vista por essa óptica, a organização judiciária conta com reduzida contribuição de sua própria gestão interna para a promoção de sua estabilidade administrativa. Assim, por ter uma gestão interna enfraquecida, essa organização depende quase exclusivamente de sua gestão externa (ou dos esforços voltados à amenização de choques com o ambiente externo) e de sua estruturação (representada por hierarquias que seguem o estilo de "burocracia weberiana") para lidar com o ambiente e suas ameaças.

Consideradas as observações de Meier e O’Toole, percebe-se que um lado negativo de a organização judiciária depender tão fortemente da gestão externa na composição de suas diretrizes de gestão é que a mesma concentra-se em seguir majoritariamente normas judiciais na prática de sua gestão interna. Esse fenômeno é em parte originado no fato de serem demandados julgamentos imparciais do juiz, em que não é cabível a exigência de previsibilidade nas decisões judiciais. Essa característica, desejável à função judiciária, torna-se um problema

\footnotetext{
${ }^{4}$ A definição de "gestão interna” usada por O’Toole e Meier (apud Meier, 2007:4) engloba também o estabelecimento de metas, a criação de incentivos aos funcionários, a estruturação de processos de trabalho e a gestão de pessoas na organização.
} 
quando, na atuação do juiz como administrador, sua conduta judicial se estende do campo processual para o administrativo (Nalini, 2006), e o mesmo passa a proceder de forma a evitar a previsibilidade e o planejamento, ambos necessários ao exercício da atividade administrativa. Em outras palavras, na administração do Judiciário brasileiro se observa um considerável atrito institucional entre os princípios da legalidade e da eficiência.

Com relação a tentativas de reações a essa problemática, é no início da década de 1990 que começa a tramitar no Congresso Nacional uma proposta de Emenda Constitucional que visava implementar a "Reforma do Judiciário". Após mais de uma década de tramitação, ${ }^{5}$ é aprovada, em 30 de dezembro de 2004, a EC no 45/2004. Uma das maiores realizações provenientes dessa Emenda, se observados os temas tratados na presente pesquisa, foi a criação do Conselho Nacional de Justiça (CNJ), ${ }^{6}$ que veio a ser instalado em junho de 2005. O órgão surge com a tarefa principal de controlar as atividades administrativas e financeiras das unidades do Poder Judiciário brasileiro. Em meio a essa atribuição, o CNJ tem a tarefa de, em âmbito nacional, lançar diretrizes, elaborar instrumentos e operar o sistema de mensuração de desempenho do Poder Judiciário brasileiro. Segundo o art. 14 da Resolução nํ 76/2009 (CNJ, 2009a), esse sistema abrange os indicadores estatísticos presentes no relatório Justiça em números e os indicadores do Planejamento Estratégico Nacional. De acordo com a edição referente ao ano de 2008, o relatório Justiça em números tem por objetivo geral buscar "a ampliação do processo de conhecimento do Poder Judiciário, demonstrado não apenas por meio de dados estatísticos, mas principalmente mediante indicadores capazes de retratar o desempenho dos tribunais" (CNJ, 2009b:7). Em seguida, é informado que "os indicadores do Justiça em números têm por objetivo a obtenção de informações de gestão dos órgãos da Justiça" (CNJ, 2009b:8), e que "estes dados são utilizados pelo Conselho Nacional de Justiça, por meio do uso de indicadores para orientar o planejamento estratégico e permitir a realização de diagnósticos sobre a situação do Poder Judiciário" (CNJ, 2009b:8).

\subsection{O Justiça em números}

O relatório Justiça em números reúne dados estatísticos relativos à Justiça Federal, Estadual e do Trabalho, que são assim apresentados:

\footnotetext{
${ }^{5}$ Uma descrição detalhada do trâmite percorrido pela EC nำ 45/2004 no Congresso Nacional pode ser encontrada em Sadek e Arantes (2001).

${ }^{6}$ Outras realizações trazidas pela EC no ${ }^{45 / 2004}$ (Brasil, 1988) podem ser elencadas: criação do Conselho Nacional do Ministério Público (art. 103-A); criação de Ouvidorias em âmbito nacional e estadual no Judiciário (art. 103) e no Ministério Público (art. 103-A); criação da "Justiça Itinerante" no âmbito dos Tribunais Regionais Federais (art. 107), dos Tribunais Regionais do Trabalho (art. 115) e dos Tribunais de Justiça dos Estados (art. 125); garantia de autonomia funcional, administrativa e financeira concedida às Defensorias Públicas Estaduais (art. 134); criação das súmulas vinculantes (art. 103-A).
} 
- Justiça Federal — referentes às cinco regiões ${ }^{7}$ sob o controle dos Tribunais Regionais Federais (TRFs);

- Justiça do Trabalho - referentes às 24 regiões $^{8}$ sob o controle dos Tribunais Regionais do Trabalho (TRTs);

- Justiça Estadual - referentes a cada estado da federação (mais o Distrito Federal) sob o controle dos Tribunais de Justiça (TJs).

Com relação aos temas relacionados a cada grupo de dados, o Justiça em números se organiza de acordo com as seguintes categorias gerais (CNJ, 2009a):

- Insumos, dotações e graus de utilização - grupo de indicadores que reúne dados sobre despesas, pessoal, recolhimentos/receitas, informática e área física destinada à prestação jurisdicional;

- Litigiosidade e carga de trabalho - refere-se à entrada de novos processos judiciais, à carga de trabalho dos magistrados, à taxa de congestionamento processual, à taxa de recorribilidade externa e interna e à taxa de reformas da decisão;

- Acesso à justiça — trata da despesa com assistência judiciária gratuita e do quantitativo de pessoal atendido nas unidades judiciais;

v Perfil das demandas - busca levantar a participação governamental nas demandas judiciais.

O Justiça em números se configura como um instrumento administrativo relativamente novo, além de se autorreconhecer como estando em construção e buscando constantes atualizações e aprimoramentos (CNJ, 2009b:10). Atualmente há oito edições publicadas do relatório, relativas aos anos de 2003 a 2010.

Por sua vez, tomando-se informações como aquelas publicadas no Justiça em números, a prestação jurisdicional pode ser considerada um processo produtivo, pois apresenta os fatores de insumos (processos novos) e produtos gerados (sentenças) por unidades de organização

\footnotetext{
${ }^{7}$ Não correspondentes às cinco regiões geográficas da divisão política do Brasil. As cinco regiões da Justiça Federal abrangem, respectivamente, os seguintes estados e o Distrito Federal (CNJ, 2009b:8): 1ª — Acre, Amapá, Amazonas, Bahia, Goiás, Maranhão, Mato Grosso, Minas Gerais, Pará, Piauí, Rondônia, Roraima, Tocantins e Distrito Federal; $2^{\text {a }}$ - Espírito Santo e Rio de Janeiro; $3^{a}$ - Mato Grosso do Sul e São Paulo; $4^{a}$ — Paraná, Rio Grande do Sul e Santa Catarina; $5^{a}$ - Alagoas, Ceará, Paraíba, Pernambuco, Rio Grande do Norte e Sergipe.

${ }^{8}$ As 24 regiões da justiça do trabalho abrangem, respectivamente, os seguintes estados/municípios e o Distrito Federal

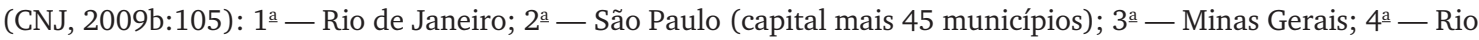

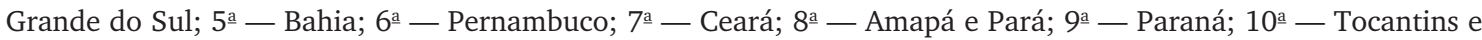

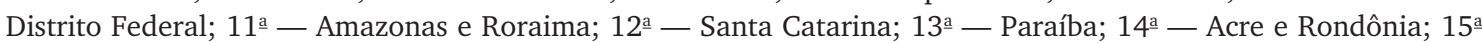
— São Paulo (Campinas mais 598 municípios do interior e do litoral do Estado); 16a — Maranhão; 17a — Espírito

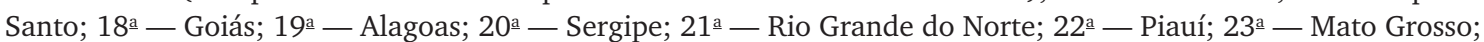
$24^{a}$ - Mato Grosso do Sul.
} 
judiciária. Tal fato permite a aplicação da metodologia de análise produtiva DEA, utilizandose os dados estatísticos trazidos pelo citado relatório gerencial.

\section{A Análise Envoltória de Dados (DEA)}

\subsection{A produção}

Um processo produtivo é caracterizado por atividades que utilizam uma determinada quantidade de recursos para produzir certa quantidade de produtos. Na teoria econômica os processos produtivos, que podem ser expressos por uma função de produção, representam relações de recursos e produtos de uma organização.

As funções de produção são as bases da análise de eficiência. Considerações em torno dessas funções visam a definir relações entre insumos e produtos; essas relações são denominadas "retornos de escalas".

Conforme Batista (2006), os retornos de escalas podem ser:

v Retornos Constantes de Escalas: os insumos aumentam ou diminuem numa mesma proporção dos produtos. Quando os insumos aumentam ou diminuem num fator X, sendo X um escalar positivo, a produção irá aumentar ou diminuir por este mesmo fator X. Um aumento do consumo leva a um aumento na mesma proporção do nível de produção.

v Retornos não Crescentes de Escalas: uma tecnologia apresenta retorno não crescente de escala se, ao multiplicar a quantidade de insumos por um fator $\mathrm{X}>1$, os produtos serão multiplicados por um fator $X^{\prime} \leq X$. Com o aumento do consumo, a proporção de aumento na produção é menor ou igual.

v Retornos não Decrescentes de Escalas: ao multiplicar a quantidade de insumos por um fator $\mathrm{X}>1$ os produtos serão multiplicados por um fator $\mathrm{X}$ ' $\geq \mathrm{X}$. Com o aumento do consumo, a produção aumenta numa proporção maior ou igual.

v Retornos Variáveis de Escalas: nesse caso não se segue nenhum padrão, ou seja, quando os insumos são multiplicados por um fator X, a produção pode seguir qualquer comportamento em relação a esse fator.

A figura 1 ilustra os tipos de retornos de escalas:

A Análise Envoltória de Dados (DEA) teve seu início em 1957 com o estudo desenvolvido por M. J. Farrell. Tendo como motivo a necessidade de desenvolver melhores métodos e modelos para avaliação da produtividade, ele propôs um conceito e um método para medir a eficiência técnica de firmas e a eficiência técnica de indústrias (Farrell, 1957).

A principal contribuição de Farrell diz respeito ao conceito de eficiência técnica. Ele mostra a ideia da medida de eficiência técnica como diferente da eficiência alocativa e propõe um método de medição dessa eficiência, denominado de medida radial. Abordou também o caso de retorno constante de escala, bem como citou as diferenças para o caso de retornos variáveis. 
Figura 1

Tipos de retornos de escalas

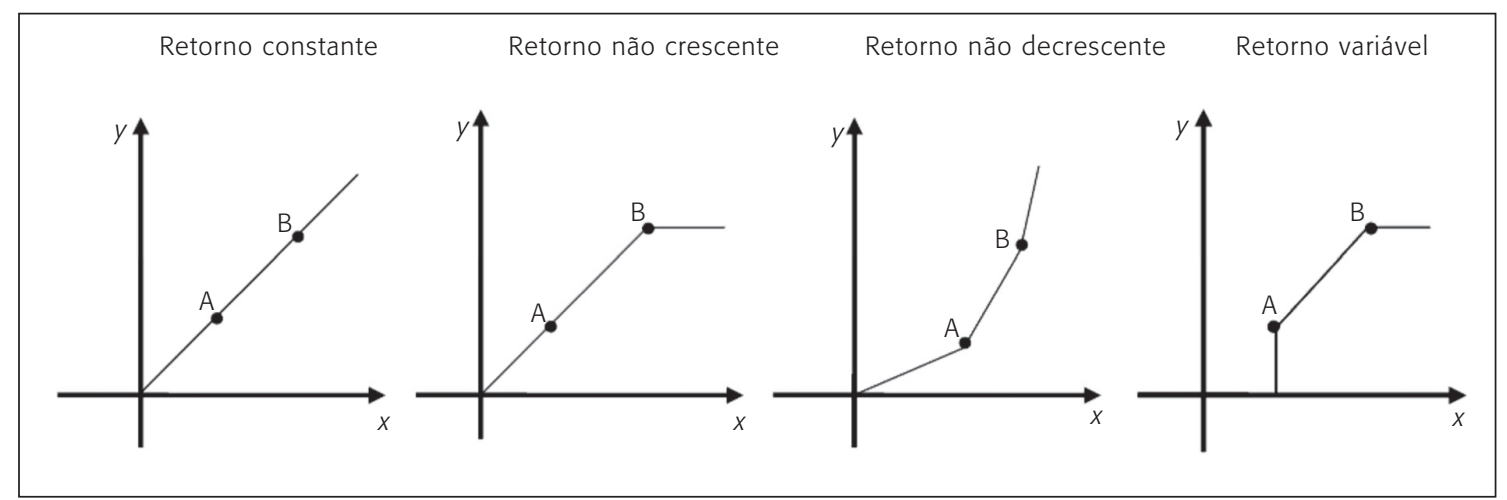

Fonte: Brunnetta (2004).

De acordo com Cooper e colaboradores (2004), Farrell argumentava que tinha problemas em obter as medidas de produtividades, pois eram muito restritas e falhavam quando se desejava determinar uma medida de eficiência global ao se combinar medidas de múltiplos inputs (insumos).

Assim, para resolver as inadequações de determinar índices de produtividade de trabalho, produtividade de capital etc., Farrell (1957) propôs uma análise aproximada que poderia ser aplicada em organizações produtivas. Dentro desse contexto, ele estendeu o conceito de produtividade para um conceito mais geral de eficiência.

A eficiência, segundo Batista (2006), pode ser definida como a comparação do que foi produzido com o que poderia ter sido produzido utilizando-se os mesmos recursos.

Conforme Brunnetta (2004), em 1951 foi criado o conceito de eficiência (Pareto-Koopmans), no qual "uma organização pode ser dita completamente eficiente se, e somente se, não for possível aumentar nenhum insumo ou produto sem diminuir algum outro insumo ou produto".

Baseado nos trabalhos de Koopmans, Farrell propôs o conceito de função fronteira; partindo da função produção, essa função foi denominada de "Isoquanta de Fronteira".

Pindick e Rubinfeld (2002) definem a isoquanta como uma curva que mostra todas as combinações possíveis de insumos que geram o mesmo volume de produção. Como a verdadeira isoquanta é desconhecida, utilizam-se dados de insumos e produtos utilizados por diversas organizações de um mesmo ramo para estimação da isoquanta.

Isto considerado, a eficiência pode ser dividida em duas dimensões (Coelli et al., 1997):

- Eficiência Técnica - mede a proximidade entre a quantidade de um determinado produto que uma unidade produtiva produz e a quantidade máxima que tal unidade poderia produzir com um determinado nível de insumos disponíveis. 
- Eficiência Alocativa - verifica se a unidade produtiva emprega uma combinação de insumos de custos mínimos, para produzir o nível observado de produtos, dados os preços relativos praticados.

Conclui-se, portanto, que a eficiência técnica está associada à melhor prática e a eficiência alocativa sinaliza se os recursos utilizados estão sendo empregados de forma otimizada, visando-se minimizar os custos de produção (Brunnetta, 2004).

\subsection{O uso da Análise Envoltória de Dados}

Segundo Kassai (2002), Charnes, Cooper e Rhodes, em 1978, generalizaram os estudos de Farrell tanto no sentido de trabalhar com múltiplos insumos e múltiplos produtos, quanto de obter um indicador que atendesse ao conceito de eficiência de Pareto-Koopmans. Essa foi a origem da técnica de construção de fronteiras de produção e indicadores da eficiência produtiva conhecida como Date Envelopment Analysis (DEA).

A DEA, conforme Banker e colaboradores (apud Kassai, 2002), "é a utilização da programação matemática para obter avaliações ex post facto da eficiência relativa dos resultados dos gestores, quer tenham sido planejados ou executados".

O modelo desenvolvido em 1978 por Charnes, Cooper e Rhodes para estimar a eficiência técnica foi denominado CCR (abreviatura de Charnes, Cooper e Rhodes, sobrenomes de seus autores).

Esse modelo emprega a programação linear para, partindo da eficiência técnica proposta por Farrell em 1957, desenvolver um modelo que atenda a casos com múltiplos produtos/ insumos, com a construção de um único produto virtual e um único insumo virtual (Charnes e colaboradores, apud Kassai, 2002).

Esta nova eficiência técnica é dada pela equação (1):

$$
\text { Eficiência técnica }=\frac{\text { Soma ponderada dos produtos }}{\text { Soma ponderada dos insumos }}=\frac{\sum_{r} u_{r} y_{r}}{\sum_{i} v_{i} x_{i}}
$$

Onde $u_{r}$ e $v_{i}$ são os pesos atribuídos à quantidade $y_{r}$ do produto $r$ e $x_{i}$ do insumo $i$ respectivamente. Os pesos podem ser atribuídos de acordo com a relevância do produto ou insumo em questão.

Qualquer processo que converte insumo em produto pode ser avaliado pela técnica DEA. Devido à larga aplicação da técnica, o termo adotado pelas entidades que utilizam recursos transformando-os em produtos é a sigla DMU (Decision Making Units) ou Unidades que Tomam Decisões. 
Genericamente, uma DMU é uma entidade responsável por converter inputs (insumos) em outputs (produtos), sendo sua performance avaliada. Nas aplicações de gestão, as DMUs podem incluir bancos, hospitais, escolas, repartições etc.

Segundo Brunnetta (2004), os modelos adotados pela DEA podem ter três orientações:

• Orientação ao Insumo: reduzir os insumos sem alterar o nível dos atuais produtos;

v Orientação ao Produto: aumentar os produtos, mantendo fixo o nível de insumos;

v Orientação ao Insumo e Produto: aumentar ao máximo a produção diminuindo ao mínimo os insumos.

O modelo CCR original trabalha com retornos constantes de escalas e, conforme Paiva (2000), suas equações são dadas por (2) e (3).

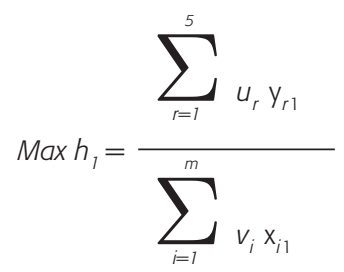

Sujeito a:

$\frac{\sum_{r=1}^{5} u_{r} y_{r 1}}{\sum_{i=1}^{m} v_{i} x_{i 1}} \leq 1$ para todo $j=1,2, \ldots, n$

$u_{r} \geq 0, r=1,2, \ldots, s$

$v_{i} \geq 0, i=1,2, \ldots, m$

Onde:

$h_{1}=$ taxa de eficiência relativa da $\mathrm{DMU}_{1}$;

$\mathrm{y}_{\mathrm{rj}}=$ quantidade de produto observado $\mathrm{r}$ da unidade $\mathrm{j}$;

$\mathrm{x}_{\mathrm{ij}}=$ quantidade de insumo observado i da unidade $\mathrm{j}$;

$u_{r}=$ variável de decisão que representa o peso dado ao produto r;

$v_{i}=$ variável de decisão que representa o peso dado ao insumo i;

$y_{r 1}=$ quantidade de produto $\mathrm{r}$ da DMU que está sendo testada;

$x_{\mathrm{i} 1}=$ quantidade de insumo i da DMU que está sendo testada;

$n=$ número de unidades; 
$s=$ número de produtos e

$m=$ número de insumos.

O modelo apresentado na equação 2 pode ser transformado em uma forma linear comum para que os métodos de programação linear possam ser aplicados. Para tal, atribui-se um valor constante ao denominador da referida equação (Cooper et al., 2004).

De acordo com Batista (2006), a eficiência das DMUs vai depender da escolha dos pesos, na medida tradicional de eficiência. Os pesos são considerados constantes através das variáveis de entrada e saída. A DEA seleciona os pesos que maximizam a eficiência de cada DMU sob a restrição de que nenhum peso deve ser negativo e o resultado da eficiência não deve ser maior que a unidade.

A seleção dos pesos é, ao mesmo tempo, um ponto fraco e um ponto forte na análise. É fraca, pois numa simples seleção de pesos uma DMU pode ser considerada eficiente. Por outro lado é forte quando uma DMU pode ser considerada ineficiente mesmo recebendo os pesos mais favoráveis em sua medida de eficiência.

O modelo CCR assume que o aumento dos produtos é proporcional ao aumento dos insumos para quaisquer escala de produção. Banker, Charnes e Cooper introduziram, assim, o modelo BCC, também conhecido como VRS (Variable Returns to Scale), admitindo que a tecnologia de produção exponha retornos crescentes, retornos decrescentes, bem como retornos constantes (Abel, 2000).

A suposição de retornos constantes de escala só deve ser feita quando todas as DMUs estão operando numa escala ótima. Porém, devido a imperfeições de mercado e restrições financeiras, as DMUs acabam não operando na escala ótima. E, nessa situação, o uso do modelo CCR pode resultar em medidas de eficiência técnica confundidas pelas eficiências de escala (Casu e Molyneux, apud Abel, 2000).

Dessa forma, o modelo BCC suaviza a suposição de retornos constantes de escala, admitindo que a escala de operação afeta a relação entre entrada e saída. Isso é feito adicionandose a variável livre $w$ ao modelo, da seguinte maneira (Batista, 2006):

$$
\operatorname{Max} h_{l}=\sum_{r=1}^{s} u_{r} y_{r 1}+w
$$

sujeito a:

$$
\begin{aligned}
& \sum_{i=1}^{m} v_{i} x_{i 1}=1 \\
& \sum_{r=1}^{s} u_{r} y_{r j}-\sum_{i=1}^{m} v_{i} x_{i j}+w \leq 0 \text {, para todo } j=1,2, \ldots, \mathrm{n}
\end{aligned}
$$


$-u_{r} \leq-e, r=1,2, \ldots, n$

$-v_{i} \leq-e, i=1,2, \ldots, m$

A DEA, sendo um método não paramétrico que determina a curva de eficiência por meio de programação matemática de otimização, não necessitando de nenhuma relação funcional entre os insumos e produtos, apresenta algumas limitações que devem ser consideradas:

、 A técnica é muito susceptível às observações extremas e aos erros de medidas;

v Torna-se difícil formular hipóteses estatísticas;

v Problemas extensos podem levar a um tempo computacional elevado;

、 A estimação do desempenho relativo é boa, porém converge muito vagarosamente para o desempenho absoluto.

\section{Metodologia}

O presente estudo, de caráter exploratório e natureza quantitativa e qualitativa, utilizou-se, para sua operacionalização, do escopo metodológico da análise de documentos. Segundo Spink (1999), os documentos considerados de domínio público refletem duas práticas discursivas: como gênero de circulação, enquanto artefatos do sentido de tornar público, e como conteúdo, em relação àquilo que está impresso em suas páginas. Nesse sentido, ressalta Spink (1999:126):

Os documentos de domínio público, como registros, são documentos tornados públicos, sua intersubjetividade é produto da interação com outro desconhecido, porém significativo e frequentemente coletivo. São documentos que estão à disposição, simultaneamente traços de ação social e a própria ação social.

Os meios de investigação utilizados para o levantamento de dados envolveram pesquisa documental e bibliográfica. Utilizaram-se, portanto, como forma de evidência, os dados publicados no relatório Justiça em números referentes aos anos de 2007 e 2008, bem como outros trabalhos voltados para a temática de análise de eficiência e da gestão do Poder Judiciário.

Serviu-se de alguma das variáveis empregadas pelo CNJ, consideradas mais significativas, no cálculo de indicadores de desempenho do Judiciário nacional. O universo de pesquisa escolhido foi aquele formado pelos 27 Tribunais de Justiça estaduais. Tal escolha se deu pelo fato de os mesmos responderem pela maior demanda de acesso à Justiça pela população brasileira. Também foi definido outro recorte metodológico quanto à utilização de dados provenientes do $1^{\circ}$ grau de jurisdição. Esses representam a primeira instância de decisão judicial. 
Vale ressaltar, também, que a eficiência da Justiça Estadual do Ceará foi escolhida para ser o referencial específico de comparação com os demais estados. Tal escolha se faz pela maior acessibilidade dos autores junto aos dados estatísticos produzidos pelo Tribunal de Justiça do referido estado.

Todos os procedimentos foram desenvolvidos com suporte nas recomendações de autores especialistas nas técnicas utilizadas (Kassai, 2002; Senra et al., 2007; Peña, 2008) e foram realizados por meio do software DEA — Solver Professional Version 7.0.

\section{Análise de resultados através da DEA}

O presente trabalho contempla uma análise da eficiência sobre os 27 Tribunais de Justiça Estadual do Brasil em que foram consideradas as variáveis dos dados contidos na publicação Justiça em números de 2007 e 2008 (1ํo Grau) do Conselho Nacional de Justiça (CNJ, 2010).

As variáveis selecionadas para a análise da eficiência foram as seguintes:

Inputs:

v Despesa total da Justiça Estadual (R\$) (DespTotal);

v Total de Pessoal Auxiliar (Tot Pessoal Aux);

v Gastos com Informática (R\$) (GInf);

> Casos Novos;

จ Total de Magistrados;

Recursos Internos.

Outputs:

、 Custas e Recolhimentos Diversos (R\$);

$\checkmark$ Sentenças.

Utilizou-se para análise dos dados neste trabalho o modelo CCR orientado para Outputs.

As tabelas 2 e 3 mostram os resultados de eficiência por estados para os anos de 2007 e 2008 da Instância 1ํo grau.

Como mencionado e justificado anteriormente, o cenário para exemplificar o uso da DEA é o estado do Ceará nos anos de 2007 e 2008. Assim, têm-se as seguintes análises. 
Tabela 2

Eficiência dos Tribunais de Justiça (2007)

\begin{tabular}{|c|c|c|}
\hline Class. & TJ & Eficiência \\
\hline 1 & Sergipe & $100 \%$ \\
\hline 2 & Rio de Janeiro & $100 \%$ \\
\hline 3 & Piauí & $100 \%$ \\
\hline 4 & Minas Gerais & $100 \%$ \\
\hline 5 & Goiás & $100 \%$ \\
\hline 6 & São Paulo & $99,50 \%$ \\
\hline 7 & Santa Catarina & $95,22 \%$ \\
\hline 8 & Rio Grande do Sul & $93,81 \%$ \\
\hline 9 & Tocantins & $91,80 \%$ \\
\hline 10 & Bahia & $78,17 \%$ \\
\hline 11 & Mato Grosso do Sul & $70,68 \%$ \\
\hline 12 & Paraná & $69,27 \%$ \\
\hline 13 & Rondônia & $68,81 \%$ \\
\hline 14 & Amapá & $57,28 \%$ \\
\hline 15 & Amazonas & $54,66 \%$ \\
\hline 16 & Mato Grosso & $54,58 \%$ \\
\hline 17 & Espírito Santo & $52,25 \%$ \\
\hline 18 & Pará & $44,79 \%$ \\
\hline 19 & Pernambuco & $42,78 \%$ \\
\hline 20 & Maranhão & $41,88 \%$ \\
\hline 21 & Acre & $41,34 \%$ \\
\hline 22 & Ceará & $38,54 \%$ \\
\hline 23 & Paraíba & $38,13 \%$ \\
\hline 24 & Distrito Federal & $33,94 \%$ \\
\hline 25 & Rio Grande do Norte & $33,32 \%$ \\
\hline 26 & Alagoas & $30,32 \%$ \\
\hline 27 & Roraima & $20,62 \%$ \\
\hline
\end{tabular}

Fonte: Elaboração dos autores.
Tabela 3

Eficiência dos Tribunais de Justiça (2008)

\begin{tabular}{|c|c|c|}
\hline Class. & TJ & Eficiência \\
\hline 1 & Sergipe & $100 \%$ \\
\hline 2 & São Paulo & $100 \%$ \\
\hline 3 & Santa Catarina & $100 \%$ \\
\hline 4 & Amapá & $100 \%$ \\
\hline 5 & Rondônia & $100 \%$ \\
\hline 6 & Rio Grande do Sul & $100 \%$ \\
\hline 7 & Rio de Janeiro & $100 \%$ \\
\hline 8 & Piauí & $100 \%$ \\
\hline 9 & Minas Gerais & $100 \%$ \\
\hline 10 & Goiás & $100 \%$ \\
\hline 11 & Tocantins & $97,22 \%$ \\
\hline 12 & Bahia & $96,00 \%$ \\
\hline 13 & Acre & $91,88 \%$ \\
\hline 14 & Paraná & $82,99 \%$ \\
\hline 15 & Mato Grosso do Sul & $72,76 \%$ \\
\hline 16 & Pará & $64,76 \%$ \\
\hline 17 & Roraima & $62,35 \%$ \\
\hline 18 & Mato Grosso & $61,32 \%$ \\
\hline 19 & Pernambuco & $61,03 \%$ \\
\hline 20 & Paraíba & $59,09 \%$ \\
\hline 21 & Ceará & $56,68 \%$ \\
\hline 22 & Espírito Santo & $55,44 \%$ \\
\hline 23 & Maranhão & $54,29 \%$ \\
\hline 24 & Rio Grande do Norte & $48,57 \%$ \\
\hline 25 & Distrito Federal & $44,04 \%$ \\
\hline 26 & Amazonas & $41,71 \%$ \\
\hline 27 & Alagoas & $31,66 \%$ \\
\hline
\end{tabular}

Fonte: Elaboração dos autores.

As tabelas 4 e 5 comparam as projeções das variáveis selecionadas do 1o grau da Justiça estadual, relativas aos anos de 2007 e 2008, com os valores efetivos para o caso do estado do Ceará. Em que:

- Efetivo: valor (real) obtido pelo Ceará para a variável;

- Projeção: valor projetado (valor desejável para a variável);

v Diferença: valor da diferença entre o efetivo e o projetado. 
Para o ano de 2007, a variável "recursos internos no 1o grau" foi excluída por estar indisponível para o Ceará e alguns estados e por apresentar baixa correlação com as demais variáveis utilizadas no modelo.

Tabela 4

Resultados "Efetivo versus Projeção" (2007)

\begin{tabular}{|lcccc|}
\hline \multicolumn{1}{|c}{ Variáveis } & \multicolumn{1}{c}{ Efetivo } & Projeção & Diferença & \% Diferença \\
\hline Desp. Total (R\$) & $449.537 .153,62$ & $378.748 .294,84$ & $-70.788 .858,77$ & $-15,75 \%$ \\
Gastos Inf. (R\$) & $5.837 .217,64$ & $3.699 .898,27$ & $-2.137 .319,37$ & $-36,62 \%$ \\
Pes. Auxiliar & 4.983 & 4.983 & 0 & $0 \%$ \\
Casos Novos 10 Grau & 198.789 & 195.088 & $-3.701,02$ & $-1,86 \%$ \\
Magistrados 1ㅇ Grau & 305 & 174 & -131 & $-43,01 \%$ \\
Casos Pendentes 1ㅇ & 575.770 & 350.577 & $-225.193,07$ & $-39,11 \%$ \\
Custas Rec. Diversos(R\$) & 24.871 .592 & 64.537 .607 & $39.666 .016,00$ & $159,48 \%$ \\
Sentenças 10 Grau & 183.008 & 474.875 & 291.867 & $159,48 \%$ \\
\hline
\end{tabular}

Fonte: Elaboração dos autores.

Tabela 5

Resultados “Efetivo versus Projeção" (2008)

\begin{tabular}{|lrccc|}
\hline \multicolumn{1}{|c}{ Variáveis } & \multicolumn{1}{c}{ Efetivo } & Projeção & Diferença & \% Diferença \\
\hline Desp. Total (R\$) & 478.370 .600 & 478.370 .600 & 0 & $0 \%$ \\
Gastos. Inf (R\$) & 9.032 .585 & $7.717 .527,22$ & $-1.315 .057,78$ & $-14,56 \%$ \\
Pes. Auxiliar & 4.681 & 4.681 & 0 & $0 \%$ \\
Casos Novos 10 Grau & 234.414 & 234.414 & 0 & $0 \%$ \\
Magistrados 1ㅇ Grau & 309 & 266 & -43 & $-13,92 \%$ \\
Casos Pendentes 1ㅇ & 626.056 & 626.056 & 0 & $0 \%$ \\
Recursos Internos 10 & 6.586 & 3.489 & -3.097 & $-47,02 \%$ \\
Custas Rec. Diversos (R\$) & 45.030 .563 & $79.442 .745,33$ & $34.412 .182,33$ & $76,42 \%$ \\
Sentenças 1ㅇ Grau & 189.305 & 333.971 & 144.666 & $76,42 \%$ \\
\hline
\end{tabular}

Fonte: Elaboração dos autores.

As projeções geradas pelo programa mostram que as despesas em 2007 foram superiores ao valor projetado de acordo com o nível de eficiência encontrado e que, em 2008, o 
valor mostrou-se adequado para o grau de eficiência alcançado pela Justiça do estado. Para magistrados, os resultados sugerem uma drástica redução no número de magistrados, podendo, por outro lado, esse resultado ser interpretado como o número de magistrados que, em média, efetivamente seria necessário para atingir o grau de eficiência alcançado pela Justiça do estado. Para que a Justiça do Ceará alcançasse o grau de eficiência total, seria necessário, entre outros fatores, que o número de sentenças experimentasse um aumento da ordem de $76,42 \%$.

A figura 2 mostra a fronteira de eficiência dos estados (para o ano de 2008). Na linha da fronteira estão representados os estados com 100\% de eficiência. Abaixo, encontram-se o Ceará e mais dois estados, os três devidamente ligados a outros localizados na fronteira que lhes servem de referência.

Figura 2

Fronteira de eficiência dos estados

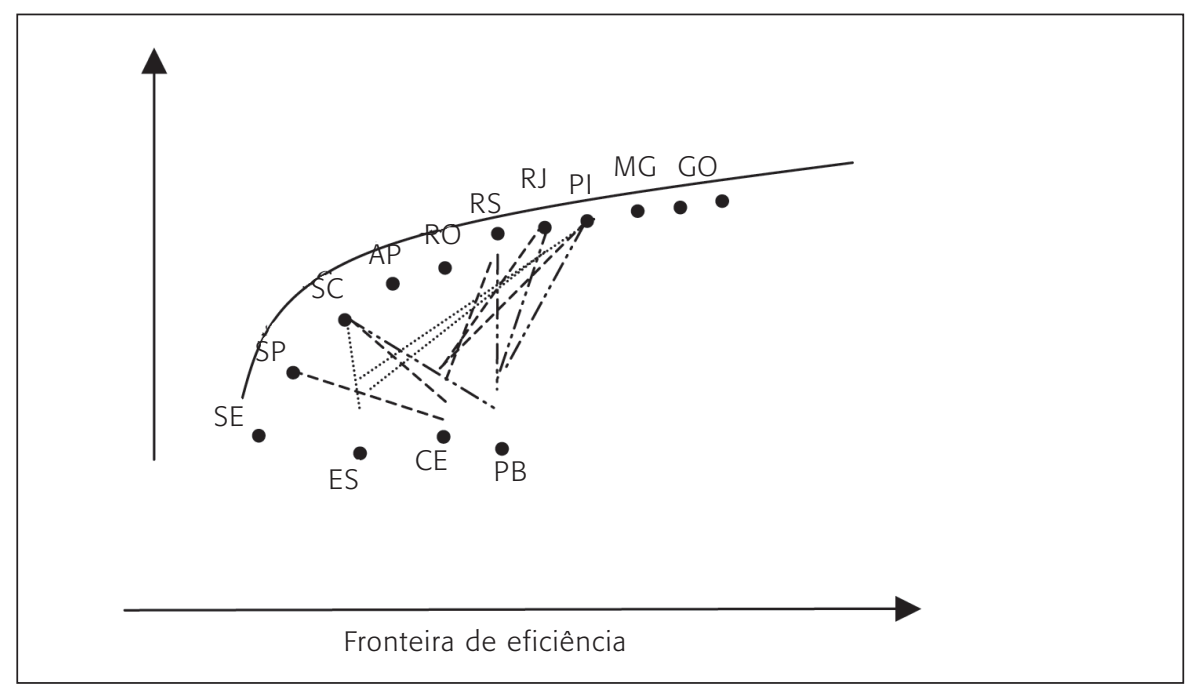

Fonte: Elaboração dos autores.

Em quantidades de tribunais, aqueles tidos como eficientes servem de referência para os demais. Por exemplo, em 2007, o Tribunal de Justiça de Minas Gerais é referência (benchmark) para 20 outros estados, enquanto o Tribunal do Piauí, em 2008, é referência para 17, conforme mostram as tabelas 6 e 7 .

Como mencionado anteriormente, a técnica DEA, sendo um método não paramétrico que determina a curva de eficiência através de programação matemática de otimização, apresenta algumas limitações que devem ser consideradas. Uma delas é o fato de a técnica avaliar somente o conjunto de dados em questão, não servindo para inferências futuras, por exemplo, resultados de 2007 não poderão ser generalizados para anos posteriores (2008, 2009 etc.). 
Tabela 6

Tribunais Referências (2007)

\begin{tabular}{|l|c|}
\hline Goiás & 0 \\
Minas Gerais & 20 \\
Piauí & 0 \\
Rio de Janeiro & 14 \\
\hline
\end{tabular}

Fonte: Elaboração dos autores.
Tabela 7

Tribunais Referências (2008)

\begin{tabular}{|c|c|}
\hline Amapá & 3 \\
Goiás & 4 \\
Minas Gerais & 0 \\
Piauí & 17 \\
Rio de Janeiro & 15 \\
Rio Grande do Sul & 7 \\
Rondônia & 3 \\
Santa Catarina & 8 \\
São Paulo & 4 \\
Sergipe & 1 \\
\hline
\end{tabular}

Fonte: Elaboração dos autores.

Conforme mostrado na tabela 8, para o ano de 2008, os estados que servem de referência para o Ceará são: Piauí, Rio de Janeiro, Rio Grande do Sul, Santa Catarina e São Paulo. Para atingir a eficiência 100\%, o estado do Ceará deveria despender menos esforço, caso tomasse como referência o estado de São Paulo.

Tabela 8

\section{Esforço a ser despendido pelo Ceará}

\begin{tabular}{|c|c|}
\hline TJ & Esforço (\%) \\
\hline Piauí & 125,03 \\
\hline Rio de Janeiro & 6,34 \\
\hline Rio Grande do Sul & 2,19 \\
\hline Santa Catarina & 7,96 \\
\hline São Paulo & 1,77 \\
\hline
\end{tabular}

Fonte: Elaboração dos autores.

A tabela 9 compara as variáveis selecionadas do 1o grau da Justiça do Ceará, relativas ao ano de 2008, com as variáveis dos estados que lhe poderiam, segundo o programa de avaliação DEA, servir como referência. 
Tabela 9

Efetivo versus Projeção: Ceará com os seus estados de referência

\begin{tabular}{|c|c|c|c|c|}
\hline \multirow[b]{2}{*}{ Variáveis } & \multicolumn{2}{|c|}{ CEARÁ } & \multirow{2}{*}{$\begin{array}{c}\text { SÃO PAULO } \\
\text { Efetivo/Projeção }\end{array}$} & \multirow{2}{*}{$\begin{array}{l}\text { RIO GRANDE DO SUL } \\
\text { Efetivo/Projeção }\end{array}$} \\
\hline & Efetivo & Projeção & & \\
\hline Desp. Total (R\$) & 478.370 .600 & 478.370 .600 & 4.597.543.991 & 1.212 .198 .824 \\
\hline Gastos Inf. (R\$) & 9.032 .585 & 7.717.527,22 & 135.681 .621 & 26.082 .097 \\
\hline Pes. Auxiliar & 4.681 & 4.681 & 55.727 & 13.373 \\
\hline Casos Novos 2ํ Grau & 234.414 & 234.414 & 4.597 .878 & 1.549 .287 \\
\hline Magistrados 2ํㅡrau & 309 & 266 & 1.810 & 616 \\
\hline Casos Pendentes $2^{\circ}$ & 626.056 & 626.056 & 14.609.684 & 2.615 .633 \\
\hline Recursos Internos 1으 Grau & 6.586 & 3.489 & 69.425 & - \\
\hline Custas Rec. Diversos (R\$) & 45.030 .563 & $79.442 .745,33$ & 1.256 .203 .449 & 153.051 .100 \\
\hline Sentenças $2^{\circ} \mathrm{Grau}$ & 189.305 & 333.971 & 3.075 .051 & 1.369 .062 \\
\hline
\end{tabular}

Fonte: Elaboração dos autores.

\section{Considerações finais}

A técnica apresentada permite identificar o comportamento de determinados fatores inerentes à prestação jurisdicional, possibilitando um enriquecimento na gestão de recursos, tornando-a mais científica, ágil e confiável.

O presente trabalho teve por objetivo apresentar uma análise da eficiência organizacional do segmento estadual do Judiciário brasileiro via DEA, usando os dados levantados pelo relatório Justiça em números (edições contendo dados dos anos 2007 e 2008).

Primeiramente, pode-se identificar um aumento no quantitativo de tribunais que alcançaram o nível máximo da eficiência relativa. No ano de 2007, apenas cinco tribunais estaduais alcançaram esse nível, enquanto em 2008 o índice foi alcançado por 10 tribunais. Portanto, verificando-se um aumento de $100 \%$.

Num segundo e terceiros momentos, foi apresentada a situação do Tribunal de Justiça do Estado do Ceará juntamente com uma análise dos fatores que precisariam ser ajustados para o alcance do nível máximo de eficiência. Alguns tribunais foram apresentados como referências (benchmarks) para os demais tribunais para os anos de 2007 e 2008, demonstrando quantas vezes cada tribunal era apresentado como referência. Em 2007, o Tribunal de Justiça de Minas Gerais foi apresentado como referência para 20 outros tribunais estaduais. Já em 2008, o Piauí serviu de referência para 17 organizações judiciárias.

Também foram identificados os tribunais que serviram de referência para uma melhoria da eficiência do Judiciário cearense. Verificou-se que o estado do Ceará deveria despender menos esforço $(1,77 \%)$ se tomasse como referência o estado de São Paulo. 
Seria relevante a replicação desse estudo em outros tribunais, juntamente com outros segmentos do Judiciário brasileiro, como o Eleitoral, o Trabalhista e/ou o Federal, bem como a utilização dos dados de instâncias superiores. Dessa forma, recomenda-se que outros estudos possam utilizar outros modelos da DEA sempre orientados para Outputs. Isso permite um melhor conhecimento dos pontos que necessitam de ajustes para uma melhor eficiência da prestação jurisdicional, visando principalmente um aumento do número de processos julgados.

Para finalizar, é necessário ressaltar que a análise e as sugestões, decorrentes desta metodologia, estão condicionadas às unidades e variáveis incluídas neste estudo. Qualquer unidade e/ou variável acrescentada ou excluída da análise modificarão os resultados.

\section{Referências}

ABEL, Lecir. Avaliação cruzada da produtividade dos departamentos acadêmicos da UFSC utilizando DEA (Data Envelopment Analysis). Dissertação (mestrado) - Universidade Federal de Santa Catarina, Florianópolis, 2000.

ARAGÃO, Cecília V. de. Fatores agilizadores e restritivos à atuação da Justiça do Trabalho: um estudo exploratório. Revista de Administração Pública, v. 31, n. 4, p. 183-215, 1997.

ARANTES, Rogério B. Judiciário: entre a justiça e a política. In: AVELAR, Lúcia; CINTRA, Antônio O. (Org.). Sistema político brasileiro: uma introdução. Rio de Janeiro: Konrad-Adenauer-Stiftung; São Paulo: Editora Unesp, 2007.

BARBOSA, Claudia M. Poder Judiciário: reforma para quê? Revista Âmbito Jurídico, v. 10, n. 46, 2007. Disponível em: <www.ambito-juridico.com.br/site/index.php?n_link=revista_artigos_ leitura\&artigo_id=2339>. Acesso em: 9 set. 2009.

BATISTA, Fabiana D. Avaliação da eficiência de empresas utilizando análise por envoltória de dados: uma aplicação no setor têxtil. Trabalho de conclusão de curso (graduação) - Universidade Federal de Itajubá, Itajubá, 2006.

BEHN, Robert D. Why measure performance? Different purposes require different measures. Public Administration Review, v. 63, n. 5, p. 586-606, 2003.

BRASIL. Constituição da República Federativa do Brasil. 1988. Disponível em: <www.planalto.gov. br/ccivil_03/constituicao/constituiçao.htm>. Acesso em: 10 out. 2009.

BRASIL. Plano diretor da reforma do aparelho do Estado. Brasília: Presidência da República, 1995.

BRESSER-PEREIRA, Luiz C. Da administração pública burocrática à gerencial. Revista do Serviço Público, v. 47, n. 1, p. 7-40, 1996.

BRESSER-PEREIRA, Luiz C. Reflexões sobre a reforma gerencial brasileira de 1995. Revista do Serviço Público, v. 50, n. 4, p. 5-30, 1999. 
BRUNNETTA, Marlon R. Avaliação da eficiência técnica e de produtividade usando Análise por Envoltória de Dados: um estudo de caso aplicado a produtores de leite. Dissertação (mestrado) — Universidade Federal do Paraná, Curitiba, 2004.

COELLI, Timothy J. et al. An introduction to efficiency and productivity analysis. Londres: Kluwer Academic Publishers, 1997.

CONSELHO NACIONAL DE JUSTIÇA. Justiça em números 2007: variáveis e indicadores do Poder Judiciário. Brasília: CNJ, 2008.

CONSELHO NACIONAL DE JUSTIÇA. Justiça em números 2008: variáveis e indicadores do Poder Judiciário. Brasília, CNJ, 2009b.

CONSELHO NACIONAL DE JUSTIÇA. Portal institucional. 2010. Disponível em: <www.cnj.jus.br>. Acesso em: 8 mar. 2010.

CONSELHO NACIONAL DE JUSTIÇA. Resolução n. 76, de 12 de maio de 2009. Dispõe sobre os princípios do Sistema de Estatística do Poder Judiciário, estabelece seus indicadores, fixa prazos, determina penalidades e dá outras providências. 2009a. Disponível em: <www.cnj.jus.br/index. php?option $=$ com_content\&view $=$ article\&id=7695:resolucao-no-76-de-12-de-maio-de-2009\&cati $\mathrm{d}=$ 57:resolucoes\&Itemid=1085>. Acesso em: 11 jun. 2009.

COOPER, William W. et al. Handbook on data envelopment analysis. Boston: Springer (Kluwer Academic Publishers), 2004.

COOPER, William W.; SEIFORD, Lawrence M.; TONE, Kaoru. Date envelopment analysis: a comprehensive text with models, applications, references and DEA - Solver Software. Nova York: Springer, 2007.

FARRELL, Michael J. The measurement of technical efficiency. Journal of the Royal Statistics Society. Série A, n. 120, p. 253-290, 1957.

KASSAI, Silvia. Utilização da Análise por Envoltória de Dados (DEA) na análise de demonstrações contábeis. Tese (doutorado) — Universidade de São Paulo, São Paulo, 2002.

KETTL, Donald. The global revolution in public management: driving themes, missing links. Journal of Policy Analysis and Management, v. 16, n. 3, p. 446-462, 1997.

MARTINS FILHO, Ives G. A implementação da justiça pela capacitação judicial — Participação na 4⿳亠口冋 conferência internacional sobre formação judicial. Revista LTr: Legislação do Trabalho, v. 73, n. 11, p. 1287-1308, 2009.

MEIER, Kenneth J. The public administration of politics, or what political science could learn from public administration. Political Science and Politics, v. 40, n. 1, p. 3-9, 2007.

NALINI, Renato. A rebelião da toga. Campinas: Millennium, 2006.

NOGUEIRA, José M. M. A ausência do Poder Judiciário enquanto objeto de estudo da administração pública brasileira. Revista Eletrônica Díke, v. 1, n. 1, p. 1-17, 2011. 
NOGUEIRA, José M. M. A gestão do Poder Judiciário: uma análise do sistema de mensuração de desempenho do Judiciário brasileiro. Dissertação (mestrado) — Escola de Administração de Empresas de São Paulo, Fundação Getulio Vargas, São Paulo, 2010.

PAIVA, Francisco C. de. Eficiência produtiva de programas de ensino de pós-graduação em engenharias: uma aplicação do método Análise Envoltória de Dados-DEA. Dissertação (mestrado) — Universidade Federal de Santa Catarina, Florianópolis, 2000.

PEÑA, Carlos R. Um modelo de avaliação de eficiência da administração pública através do método análise envoltória de dados (DEA). Revista de Administração Contemporânea, v. 12, n. 1, p. 83-106, 2008.

PINDICK, Robert S.; RUBINFELD, Daniel L. Microeconomia. São Paulo: Prentice Hall, 2002.

SADEK, Maria T. O Poder Judiciário na reforma do Estado. In: BRESSER-PEREIRA, Luiz C. et al. (Org.). Sociedade e Estado em transformação. Brasília: Enap, 1999. p. 410-435.

SADEK, Maria T. Principais problemas do Judiciário decorrem da falta de gestão, revela estudo da AMB. Entrevista concedida no lançamento da pesquisa "Justiça em números: Novos ângulos". 2009. Disponível em: <www.amb.com.br/imprensa/imprimir.asp?mat_id=19124> . Acesso em: 20 nov. 2009.

SADEK, Maria T.; ARANTES, Rogério B. A importância da reforma judiciária. In: SADEK, Maria T. (Org.). Reforma do Judiciário. São Paulo: Fundação Konrad-Adenauer, 2001. p. 7-21.

SENRA, Luis F. A. C. et al. Estudos sobre métodos de seleção de variáveis em DEA. Pesquisa Operacional, v. 27, n. 2, p. 191-207, 2007.

SPINK, Peter K. Análise de documentos de domínio público. In: SPINK, Mary J. (Org.). Práticas discursivas e produção de sentidos no cotidiano. São Paulo: Cortez, 1999. p. 123-152.

VIEIRA, Luciano J. M.; PINHEIRO, Ivan A. Contribuições do Conselho Nacional de Justiça para a gestão do Poder Judiciário: In: ENCONTRO NACIONAL DA ANPAD, XXXII, Rio de Janeiro. Anais eletrônicos... Rio de Janeiro: Anpad, 2008. p. 1-16.

José Marcelo Maia Nogueira é servidor da Secretaria Especial de Planejamento e Gestão do Tribunal de Justiça do Estado do Ceará. E-mail: marcelomaia30@gmail.com.

Kátia Michelle Matos de Oliveira é servidora da Secretaria Especial de Planejamento e Gestão do Tribunal de Justiça do Estado do Ceará. E-mail: michelle_ufc@yahoo.com.br.

Alan Pereira de Vasconcelos é professor das Faculdades Nordeste. E-mail: 7670@tjce.jus.br.

Leonel Gois Lima Oliveira é professor da Escola Superior de Magistratura do Estado do Ceará (Esmec). E-mail: leonelgois@gmail.com. 